\title{
Cognitive Relevance Involved in Verbal Communication: A Perspective of the Personal Experience Theory
}

\author{
Zhongxin Dai \\ College of Foreign Languages, North China Electric Power University, Changping District, Beijing, China \\ Email: zhongxindai@126.com
}

\begin{abstract}
This paper is intended to interpret, from a perspective of the Personal Experience (PE) Theory, the cognition and relevance involved in verbal communication. The process of verbal communication, based upon personal experience (PE), consists of two sub-processes that are heterogeneous in nature: the sub-process of the formation of the communicative notion $(\mathrm{CN})$, which is non-linguistic in nature, and the sub-process of verbal expression of the $\mathrm{CN}$, which is linguistic in nature. The speaker's PE enables him to turn an external context into an internal context, and develop a $\mathrm{CN}$ and an utterance image, which is then verbally expressed. In contrast, the listener's PE enables him to intelligently associate the verbal form with its meaning, form an utterance image, associate the image with his conceived context, and finally infer the speaker's CN. This theory of cognitive relevance involved in verbal communication from the perspective of PE Theory enjoys considerable advantages of powerful interpretation over other theories.
\end{abstract}

Index Terms - personal experience, verbal communication, cognition, relevance

\section{INTRODUCTION}

Broadly speaking, there are two major themes of research in pragmatics: utterance production and utterance comprehension (He \& Ran, 2001). However, the processes of utterance production and comprehension are labyrinthine in nature. Researchers had approached the issue from a variety of perspectives before the 1980s, when Sperber and Wilson published their work Relevance: Communication and Cognition. They (2001, Preface to Second Edition) examined human communication from a general view of human cognition. "Human cognition," they argued, "are geared to achieving the greatest possible cognitive effect for the smallest possible processing effort." In order to achieve this, "individuals must focus their attention on what seems to them to be the most relevant information available." To communicate is to claim an individual's attention. The information communicated is relevant to the addressee. This is the Communicative Principle of Relevance. They $(2001$, p.1) pointed out that "the study of human communication raises two questions: first, what is communicated, and second, how is communication achieved?"

The "relevance" theory does provide a framework for our understanding of the process of human verbal communication. During the process of communication, both the addresser and the addressee are, at all times, cognitively processing information from whatever is involved in the context. The cognitive mechanisms working in the process of communication are geared to judging the relevant information and factors from what they perceive in the communicators, what is communicated and the situated context. However, what is relevant in verbal communication has much to do with an individual's knowledge, attitudes, beliefs, mood, personality, and the like. The seemingly unquestionable starting point is not beyond reasonable doubt. A full understanding of the mechanisms involved in the cognitive activities in human verbal behavior requires further studies on another pair of related questions. First, why do communicators communicate what is communicated? Second, why is communication achieved the way it is achieved, including both successes and failures of communication? Only when we examine the two questions raised by Sperber and Wilson in terms of these two more fundamental questions, can we find the starting point of human communication and the cognitive relevance involved in communication.

This article attempts to reveal and account for what the above mentioned two further questions mean. Briefly, by the first question, we mean that, under normal circumstances, what a person communicates with another person can be somewhat anticipated from the former's personal experience (PE). When an individual with his particular PE meets another individual with equally particular PE, "what is to be communicated" on the part of the speaker will be automatically generated. The second question attempts to address the fact that both the addresser and the addressee employ their cognitive mechanisms for relevant information, but due to the differences between their respective PE, misunderstanding or misreading tend to occur.

\section{Verbal Communication from the Perspective of the PE Theory}

Dai (2004) formulated the PE Theory in his work The Formation and Development of Verbal Communicative 
Competence in a Foreign Language: A Perspective of the Personal Experience Theory. PE refers to whatever an individual, situated in a particular life status and equipped with certain innate mental and physical capacities, obtains in his interaction with the natural and social-cultural surroundings, including various events that he has experienced, knowledge that he has acquired, feelings and emotions that he has gone through, cognitive abilities that he has developed, and whatever that makes him differ from what he was and that will contribute to later processes of his experience acquisition.

Any individual, at any moment, is experiencing a particular and specific life situation, different from that of any other person. We are confined to it, and the lived experience affects, in one way or another, the way we feel and interact with our surroundings. Whatever one obtains from his lived experience is determined by his previous lived experience and will affect whatever he will experience. Dewey (1938) discussed two principles of experience: the principle of interaction and the principle of continuity. The first principle means that experience is both the process and the result of one's interaction with the external world; the second principle is to say that experience is continuous process; one's lived experience has a driving force, affecting the manner of his interaction with whatever he will experience.

In the course of verbal communication, each individual has his own PE. The moment the speaker meets the listener, parts of his PE relevant to the situated context come up automatically and unconsciously. For instance, the listener borrowed a book from the speaker the other day; or the speaker had heard that the listener had won the lottery; or a person that they both knew had had an accident. The reason why the speaker comes up with a topic for a conversation is that the moment the speaker meets the listener, the speaker's PE intelligently and automatically presents the part of PE relevant to the listener.

Liu $(1988,2001)$ views the process of verbal communication as a "double-layer" process, with one layer being linguistic and the other non-linguistic. Some researchers of cognitive linguistics (e.g. Langacker, 1987, 1991, 2008; Evans 2009) also adopt this "double-layer" view towards the process of language understanding and production. Liu (2001) argues that the reason why the same utterance is subject to different understandings is that different people draw different inferences when they convert the literal meaning of the utterance into contextual meaning and speaker's intention. Then why are people liable to draw different inferences from the same utterance? Liu provide two reasons: the meaning in an utterance consists of elements different in nature; and different people have different ways of cognition. Then the questions that we would like to address are: why do people have different ways of cognition, and how do cognitive models interact with different elements in the utterance?

According to Sperber and Wilson, communication is an ostensive-inferential process. In the communication process, the speaker should make his intended information explicit, and the listener associates the information with the context and infers the speaker's intention. Then how it comes that different people draw different inferences? How can we account for the following talk between husband and wife who have just quarreled?

Husband: Be careful on your way to work.

Wife: Don't worry. I won't kill myself in a car accident.

How do we interpret practical problems such as this in real verbal communication? In order to reveal the mechanisms involved in verbal communication, we need to introduce the concept of PE. Any kind of context is that of PE; any utterance is produced from PE; any understanding or inference is based upon PE, and no relevance is made without referring to $\mathrm{PE}$.

Verbal communication begins with the speaker's intention, which is brought about by his thoughts, assumptions, ideas, information, feelings, emotions, and the like, which he wants to share with the listener. For convenience, we use "communicative notion (CN)" to refer to what the speaker intends to employ language to express or convey to the listener. A CN arises out of the need of social communication. The study of verbal communication process should not just focus on the verbal communication process alone. The formation and development of the CN should also be included, and viewed as the starting point of the process of verbal communication. Otherwise, the utterance during the process of verbal communication would seem to emerge out of thin air. The generation of an utterance can be split up into two sub-processes: first, the process of generating the $\mathrm{CN}$, and second, the process of generating the form vehicle of the utterance (i.e. the process of producing the phonological form). The processes of the generation of the $\mathrm{CN}$ and the phonological vehicle are actually two levels with different nature. The former is non-linguistic in nature, and the latter linguistic in nature.

Researchers have noticed that the phenomenon of one meaning with different interpretations is the result of inferring the speaker's CN by virtue of integrating what is said and the utterance context. Sperber and Wilson (2001) proposed "contextual effects" to indicate the function of the context through cognitive operations involved in the understanding process. They (2001, pp.108-117) are most interested in the interaction between old and new information. One question addressed to this issue is: how can individuals pinpoint new information from the old? Only when the theory of PE is introduced to the analytical framework can the judging process be theoretically interpreted. Verbal communication of all kinds occurs between people with different PE. The speaker's CN, what he says and how he says it, are reflections of the characteristics of his PE. In the process of verbal communication, the same person has different CNs and hence chooses different utterances. This is because different contexts induce different parts of the speaker's PE. In the same context, different people show different communicative style. The reason for it can also be traced to their respective PE.

This theory on the verbal communication process interpreted for the perspective of PE Theory attempts to analyze 
daily routine verbal communication and to provide a clearer, more human and more practical framework for the analysis. The following figure is an overview of the architecture of the theory of verbal communication from the perspective of the PE Theory.

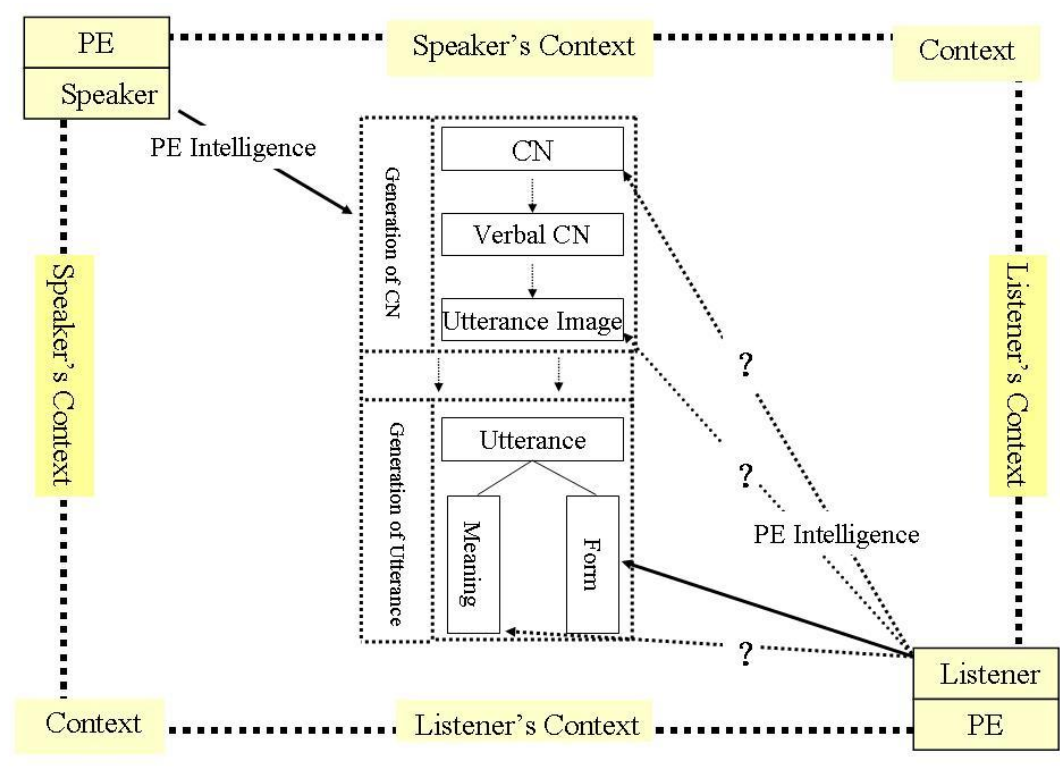

Figure 1 An overview of the Architecture of Verbal Communication

Figure 1 can be interpreted as follows:

(1) The speaker and the listener have their own respective PE. The speaker's CN is what his PE generates in a given context. Let us examine the well-known example "It is cold in here." Previous research has centered on the utterance and the context where the utterance is situated. Examination should start from the time when the speaker enters the place and feels cold, which is the very cause of his speaking "It is cold in here." The utterance originates from the coldness that the speaker feels and identifies as something that he may call as cold.

(2) In the process of verbal communication, the context is subjective rather than objective. Both the speaker and the listener exercise their PE to examine the same objective context in order to figure out what it means. The operation of the PE is effortless and automatic, and, so to speak, driven by the PE intelligence. Therefore, the same objective context becomes different versions of contexts: the speaker's subjective context and the listener's subjective context.

(3) The feeling of coldness and the PE intelligence-rendered context prompt the speaker to decide whether to express his $\mathrm{CN}$ by means of an utterance. It is most likely that he shuts the window himself, or that he pretends to huddle up in order to draw the attention of the person(s) in the situated context. If he decides to announce his feeling of the coldness with the intention of making the addressee shut the window, then his $\mathrm{CN}$ becomes verbal $\mathrm{CN}$, which means that the $\mathrm{CN}$ has become the target that the speaker aims to express in language. The verbal $\mathrm{CN}$ is still nonlinguistic in nature, as it has not yet been verbalized. He can ask the addressee in direct way to shut the window by saying "Would you mind closing the window?" The speaker's PE, the PE intelligence-rendered context and the speaker's mood at the moment, contribute to the speaker's decision on the ways of expressing the verbal CN. In typical cases, the speaker and the listener seem to be playing a guessing game, where the speaker puts an image in the picture of the shared context and let the listener guess what it means. The image has to be understood against the situated context. Therefore, what the speaker actually says is termed an utterance image. It is called "image" because it is picture-like, something that the speaker intends to draw against the background of the context and that the listener has to understand against the background of his subject context.

(4) The $\mathrm{CN}$, the verbal $\mathrm{CN}$ and the utterance image form the stage of $\mathrm{CN}$ generation, which is non-linguistic in nature, as opposed to the stage of utterance generation, which is linguistic in nature. In actual verbal communication, they are seemingly inseparable, but in cases of foreign language learning, foreign language learners often experience the separation between the verbal $\mathrm{CN}$ and the utterance generation. This is because utterances are conventionally associated with contexts. Foreign language learners seldom practice the association between the verbal $\mathrm{CN}$ in a given context and the actual expression of the utterance. There is no problem for them to form the $\mathrm{CN}$ and the verbal $\mathrm{CN}$, but problems arise when they seek utterance images.

(5) Once the speaker has decided to use the utterance image of "It is cold in here," he enters the stage of utterance generation. An utterance is like a coin with two sides. One side is the phonological form vehicle, and the other side the meaning of the form. In the course of verbal communication, the listener first hears the phonological form. A person who does not know the language will have no idea of what is said. He has heard the form, but nothing is associated with it. If a foreign language learner knows "it is" and "in here", he only has fragments of the utterance meaning, and cannot 
form a mental picture or image of the utterance. An utterance image differs from an utterance meaning in that an utterance image is a mental picture formed from a full understanding of the utterance meaning. If you do not know the meaning of the word "pistol" in "He took a pistol out of his pocket," you only form part of the picture. Furthermore, with this part of the picture, you will have no way to associate it with the context and infer the speaker's CN. With the utterance image, you not only know the conceptual meaning of the word "pistol", but also the possible danger with it.

(6) In the process of verbal communication, the starting point for the listener is the phonological form that he receives from the speaker. He, with his $\mathrm{PE}$ and linguistic knowledge, forms the utterance meaning of the utterance form, and, with the help of the PE intelligence, shapes the utterance image. Then the listener integrates the information he gets from the utterance image and relevant factors in his subjective context. This information-fusing process is also PE intelligence-mediated. In general, since the speaker's utterance image is developed from the PE-based context and PE-based CN, the listener will have no problem achieving all these with the aid of his PE intelligence. However, because the listener's PE is different, and, therefore, his context, his utterance image and his inference of the speaker's $\mathrm{CN}$ may differ from the speaker's. Hence misunderstanding or misreading may occur. The processes where these may occur are marked with "?".

\section{CONCLUSION}

Verbal communication, especially the understanding process in verbal communication, has been the research interest of philosophy, linguistics and psychology. Philosophers such as Austin (1962, 1972) and Searle (1975, 201a, 2001b) showed philosophical interest in it and developed the Speech Acts Theory. The cognition and mental mechanisms involved in the operation of the PE is incredibly elusive. Verbal communication is not just a superficial speech or social act, but a mental operation that involves relevant memory and the habitual behavior of the PE. Every individual is a physical body with his autobiographical memory of his lived process as his soul. This memory is his PE. Scholars of sociolinguistics focus on the social aspects of verbal behavior. Hymes (1979) argued that "linguistic competence", a key concept in Chomsky's theories, should be considered within the framework of "communicative competence", for linguistic competence belongs in the generation of utterance, which is the secondary stage in verbal communication. The primary stage is the CN generation. Before the speaker conducts the actual utterance, he should, first of all, examine his situated context and then determine what to say and how, when, and to whom to say it. The examination and determination work on the basis of his PE. As one's PE is his lived experience, it is the underlying soil where his beliefs and value systems grow. The underlying PE soil shapes and regulates the social and verbal behavior, through beliefs, value systems and prototypical instances from the lived experience. A habitual rude person is prone to impolite manners and violates the principle of politeness. Research should aim to explain and interpret what exists. Everything is shaped by the PE, and attitudes, beliefs, value systems, and personality are no exception. Verbal communication is a social interaction where one reveals and unfolds himself. With the PE theory, pragmatics is fused in social communication.

\section{REFERENCES}

[1] Austin J. L. (1970). Philosophical papers. Oxford: Oxford University Press.

[2] Austin, J. L. (1962). How to do things with words. Oxford: Clarendon Press.

[3] Dai, Z. (2004). The formation and development of verbal communicative competence in a foreign language: A perspective of the Personal Experience Theory. Ph.D. dissertation, Beijing Normal University.

[4] Dewey, J. (1938). Experience and education. London \& New York: Macmillan.

[5] Evans, V. (2009). How words mean: Lexical concepts, cognitive models and meaning construction. New York: Oxford University Press.

[6] He, Z \& Ran, Y. (2001). Introduction. In D. Sperber \& D. Wilson, Relevance: Communication and cognition (2 ${ }^{\text {nd }}$ edn.). Beijing: Foreign Language Teaching and Research Press, F23-F40.

[7] Hymes, D. H. (1979). On communicative competence. In C. J. Brumfit \& K. Johnson (eds.), The Communicative approach to language teaching. Oxford: Oxford University Press, 5-26.

[8] Langacker, R. W. (1987). Fundamentals of cognitive grammar: Volume I theoretical prerequisites. Stanford: Sanford University Press.

[9] Langacker, R. W. (1991). Fundamentals of cognitive grammar: Volume II theoretical prerequisites. Stanford: Sanford University Press.

[10] Langacker, R. W. (2008). Cognitive grammar: A basic introduction. Oxford: Oxford University Press.

[11] Liu, H. (1988). Verbal communication. Nanchang: Jiangxi Education Press.

[12] Liu, H. (2001). The secret of speech and intention: Exploration of the Semantic labyrinth of utterances. Beijing: China Social Sciences Press.

[13] Searle, J. R. (1975). Indirect speech acts. In P. Cole \& J. L. Morgan (eds.) Syntax and Semantics 3: Speech Acts. New York: Academic Press, 59-81.

[14] Searle, J. R. (2001a). Speech acts: An essay in the philosophy of language. Beijing: Foreign Language Teaching and Research Press.

[15] Searle, J. R. (2001b). Expression and Meaning: Studies in the Theory of Speech Acts. Beijing: Foreign Language Teaching and Research Press.

[16] Sperber, D \& Wilson, D. (2001). Relevance: communication and cognition ( $2^{\text {nd }}$ edn.). Beijing: Foreign Language Teaching and 
Research Press.

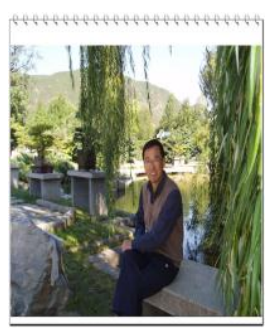

Zhongxin Dai was born in Hebei Province, China, in 1959. He received his B.A. in 1986, M.A. in English language and literature in 1989, and Ph.D. in Education in 2004, all from Beijing Normal (Teachers) University. He was a visiting scholar at Peking University from 1995 to 1996, and at Exeter University from 1999 to 2000.

$\mathrm{He}$ is currently a professor in the School of Foreign Languages, North China Electric Power University, Beijing, China. His research interests include second language acquisition, English learning and teaching, and cognitive linguistics. 